\author{
St ud i P hilos o p hi c a \\ Wratis lavien s i a \\ vol. XV, fasc. $1(2020)$ \\ https://doi.org/10.19195/1895-8001.15.1.2
}

\author{
BUKET KORKUT RAPTIS \\ ORCID: 0000-0002-0404-0910 \\ Muğla Sıtkı Koçman University
}

\title{
The Relevance of Emotions for Ethical Discourse: A Thesis in Philosophical Anthropology
}

\begin{abstract}
In this paper I propose a thesis in philosophical anthropology that aims to explain the relevance of emotions in ethical discourse. I introduce the concept of Gönül which, in Turkish language, stands primarily for the faculty of love and, generally, for that of emotions. In my analysis, I rely on the etymological connections between certain concepts in Turkish so as to understand the relevance of love in particular and emotions in general for ethical discourse. I argue that it is not the faculty of mind but that of Gönül which distinguishes humans from animals. Based on the distinction between "to understand" and "to know" in Turkish and their etymological relations with other concepts, I argue that understanding pertains to subjects, while knowledge pertains to objects. In other words, I claim that although we can understand subjects, we cannot know them, and that although we can know objects, we cannot understand them. Furthermore, given the familiar distinction between mechanical causation and teleological causation, I propose that "to know" is "to know how something works in terms of mechanical reasons" and that "to understand" is "to understand why someone acts in terms of teleological reasons." Accordingly, based on the distinction between knowledge and understanding, the distinction between mind and Gönül can be rephrased: through mind we know how an object works based on mechanical reasons and through Gönül we understand why a subject acts based on teleological reasons. This means that we can understand a subject's reasons for action only if we can sympathise with her emotions. I conclude that the realm of ethical discourse involves understanding through emotions, which is the task of the capacity of Gönül. In this sense, Gönül is a higher capacity than mind, for it presupposes the knowledge of objects but also requires understanding through emotions.
\end{abstract}


Keywords: ethical discourse, emotions, Gönül, mind, knowledge, understanding, mechanical reason, teleological reason

Ethical discourse is what we do when we aim to arrive at an ethical judgment so as to act well. In this paper, I will attempt to explain the relevance of emotions for ethical discourse. In order to do this, I will develop an outline of a philosophical-anthropological thesis based on the etymological connections in Turkish language; for I believe that there is a logos (rationality) embodied in historical languages that preserve the original etymological connections among concepts. These etymological connections among the concepts of a language reveal a particular interpretation of reality. In this sense, I aim to uncover how thinking in Turkish language provides us with a new interpretation.

My argument will refer to Aristotle's moral philosophy. I will attempt to reveal a new perspective beginning with, and in comparison, to Aristotle's approach. To begin with, in the Nicomachean Ethics (NE) Aristotle claims that the human soul consists of two parts, alogon and logon, i.e. non-rational and rational. The alogon (non-rational) part also consists of two parts: "One division of it, the vegetative, does not share in rational principle at all; the seat of the appetites and of desire in general, does in a sense participate in principle, as being amenable and obedient to it" (NE I.xiii18). But Aristotle then claims that it is possible to consider this second division of the non-rational part as rational: "If on the other hand it be more correct to speak of the appetitive part of the soul also as rational, in that case it is the rational part, which as well as the whole soul, is divided into two, the one division having rational principle in the proper sense, and in itself, the other obedient to it as a child to its father" ( $N E$ I. xiii19). This is also how Aristotle distinguishes between the virtues of intellect and those of character. While the rational part in the proper sense is the ground of intellectual virtues, the other part is the basis of character virtues. Hence, for Aristotle, character virtues, which are necessary for ethical discourse and action, belong to the appetitive part of the soul, which is also the seat of emotions.

Character virtues are well established dispositions, or one may say, character qualities, which enable one to give a proper emotional response at the right time for the right reasons. As Aristotle says, "dispositions are the formed states of character in virtue of which we are well or ill-disposed in respect of the emotions" (NE II.v.2). Aristotle claims that emotions are neither good nor bad by themselves; whether or not they are proper, depends on the situation. One may be angry for no good reason or one might be angry due to an injustice done to another person. In the latter case, it would be improper not to be angry. Accordingly, "virtue is then a settled disposition of the mind determining choice of actions and emotions consisting essentially in the observance of the mean relative to us, this being determined by principle, that is, as the prudent man would determine it" (NE II.vi.15).

Furthermore, in The Art of Rhetoric $(A R)$, Aristotle distinguishes the subject matter of rhetoric as those issues that are also the subject matter of deliberation. As I take it, deliberation is what we do in an ethical discourse. Hence rhetoric 
primarily aims at convincing an audience that a certain public decision is the best outcome of deliberation or what we call ethical discourse.

There are three important proofs or concerns that a good rhetorical discourse should pay attention to. As Aristotle explains: "The first depends upon the moral character of the speaker, the second upon putting the hearer into a certain framework of mind, the third upon the speech itself, in so far as it proves or seems to prove" ( $A R$ I 1356a3). The last kind of proof consists of enthymeme (rhetorical syllogism) and example (rhetorical induction). The second means that "the orator persuades by means of hearers, when they are aroused to emotion by speech; for the judgments we deliver are not the same when we are influenced by joy or sorrow, love or hate" ( $A R$ I 1356a5).

Furthermore, says Aristotle, "now, since proofs are effected by these means, it is evident that, to be able to grasp them, a man must be capable of logical reasoning, of studying characters and virtues, and thirdly the emotions - the nature and character of each, its origin, and the manner in which it is produced" ( $A R$ I 1356a7). And that is why, according to Aristotle, rhetoric is the "offshoot of Dialectic and the issues regarding Ethics, which may be reasonably called Politics."

These aspects of emotions, as Aristotle defines them in $N E$ and $A R$, already reveal the relevance of emotions for ethical discourse, but also raise the following question: if it is true that the right ethical judgment requires the presence of certain emotions, how shall we situate emotions? Are they rational or non-rational? Aristotle was aware that not only our choice of action but our judgment regarding ethical concerns, if they are to be right or proper, requires that we are well disposed with respect to emotions. But he was not quite sure about whether emotions should be classified as rational or not.

Those familiar with contemporary literature on emotions will know that emotions nowadays are mostly considered as involving a cognitive element. I will not discuss this literature here but will remark that some of the contributions belong to cognitive science while others adopt more philosophical approaches. It seems to me that the question of whether emotions are rational or cognitive is misleading. It is quite obvious that emotions are not irrational or do not arise without any reason. For we can understand them. But, of course, emotions are not like our ideas either. For, we do not think them, but feel them.

In order to clarify the relevance of emotions for ethical discourse, I will rather begin with a discussion of a distinctive faculty called Gönül in Turkish language. Although in the proper or narrow sense Gönül is the faculty of love, in its broader sense it refers to the faculty of emotions. In English the closest term would be "heart," but heart is an organ, not the name of a distinctive faculty. As mind stands to brain, Gönül, in Turkish, stands to heart. If we consider mind to be the capacity of brain as an organ, we may also consider Gönül as the capacity of heart as an organ. Since there is no proper translation of Gönül in English, I shall introduce the Turkish term Gönül as a technical term of my philosophical thesis.

Now, Aristotle distinguishes between theoretical reason and practical reason and most philosophers follow him in this distinction. I would rather claim that the proper distinction is between mind as the faculty of intelligence, and Gönül as the 
faculty of emotions. Mind, as I take it, results with knowledge due to thinking. In this sense, mind, as the faculty of intelligence, is actually the faculty of knowledge and thinking. Gönül, on the other hand, results with understanding due to deliberation, which is required for ethical discourse. Hence, the faculty of emotions is the faculty of understanding and deliberation, which allows one to engage in ethical discourse. It is important to note that Gönül is a higher capacity than mind, for it presupposes the presence of the capacity of mind in a living organism, but surpasses it. In this sense, as opposed to Aristotle, I rather agree with Max Scheler that intelligence is not what distinguishes humans from other animals; for there is a matter of degree in terms of intelligence among animals. Hence, as I claim, Gönül is the capacity of understanding and deliberation and allows one to engage in ethical discourse. In this sense, it is not mind but Gönül that distinguishes humans from animals. ${ }^{1}$

I shall now explain what I mean by the distinction between knowledge and understanding, and also introduce another related distinction between mechanical causation and teleological causation. In Turkish, "to know" is "bilmek," "knowledge" is "bilgi," and "science" is "bilim"; all come from the same root. Following this connection, I would like to claim that science provides us with knowledge. On the other hand, "to understand," "to explain," "meaning," "narrative," "moment," "memory," "being considerate" or "sympathetic" are related concepts coming from the same etymological root in Turkish. "To understand" is "anlamak," "to explain" is "anlatmak," "meaning" is "anlam," "narrative" is "anlatr," "moment" is "an," "memory" is "anı," "being considerate" is "anlayışl." When one says that "I understood the meaning of what you explained through the narrative of your memories" in Turkish language it is almost tautological: "Anılarının anlatısı ile anlattığının anlaminı anladim." This non-viciously circular sentence was the core of my previous work entitled The Narrative Nature of Ethical Discourse. There, I claimed that the proper means by which we understand and explain ethical judgments is narrative. What I have not done at that time, but would like to do now, is to distinguish between understanding and knowledge. To do so, one needs to distinguish between mechanical causation and teleological causation.

It is typical to claim that Aristotle was wrong in his attempt to explain nature by means of teleological causation. Modern science teaches us how to explain nature by means of mechanical causation. Now, if it is possible to distinguish the world of matter from the world of life where life also involves matter, but goes beyond it, I agree that modern science shows us how the world of matter works mechanically, and that the world of life can be investigated mechanically to the extent that it is considered to be composed of matter. But there is an aspect of life, its "autonomy," as one may call it, that goes beyond the world of matter. I want to claim that Aristotle's teleological explanation is still relevant for explaining the causes of actions in complicated life forms like us, human beings. In other words, the action of a person can only be explained with respect to a telos, end, purpose,

${ }^{1}$ For a further discussion of this thesis and the relation between Gönül and mind see my paper, in Turkish, entitled “Gönlünce Yaşamak: Güzel Bir Yaşamm İki Koşulu," Felsefelogos 53 (2014), pp. 137-157. 
or target that she aims to achieve as a result of that action. This kind of causation might also be called backward causation since the end determines the beginning.

Given this distinction between mechanical and teleological causation, I propose that "to know" is "to know how something works in terms of mechanical reasons" and "to understand" is "to understand why someone acts in terms of teleological reasons." To the extent that we reduce a life form to the level of matter, to that extent we objectify it or make it an object of science, and we can know how it works. To the extent that we elevate a life form to the level of an autonomous being, to that extent we subjectify it or make it a subject of narrative, and we can understand why it acts.

Now the distinction between mind and Gönül fits nicely to the distinction between knowledge and understanding. Through mind we know how an object works and through Gönül we understand why a subject acts. Both knowledge and understanding are in this sense "with reason" or "rational," but for different reasons; the former is mechanical, the latter is teleological.

We know how objects work and we understand why subjects act. In other words, we cannot understand why objects work and we cannot know another person; we can only understand her when we share or imitate or sympathise with her actions. To understand a subject is basically to sympathise with her emotions behind her telos that determines her action. Hence, human beings in so far as they are autonomous, are not objects of knowledge but are subjects of understanding. We can only understand the reason why a subject acts the way she does when we sympathise with her emotions behind her teleological reasoning. Hence, deliberation, which results with understanding followed by action, is teleological reasoning guided by emotions. Yes, we deliberate basically about our emotions so as to determine an understandable telos.

Coming back to the Turkish etymological relations among "understanding," "explaining," "meaning," "narrative" and "considerate" or "sympathetic," we should then make another tautological claim: "Only if we are considerate (or sympathetic) persons, we can understand what another person explains to us through narrative." In Turkish, "Sadece anlayışlı kişiler olarak başka bir kişinin anlatısı ile bize anlattığını anlayabiliriz." In other words, for the possibility of understanding we need to be a sympathiser, and we can only sympathise with other beings like us, namely, other life forms, beginning with the closest ones to the most remote ones. But we cannot sympathise with the matter, hence we cannot understand the matter. We can only know it. And unless we reduce a life form to the level of matter, we do not know a life form, we can only understand it.

What does all this have to do with the relevance of emotions for ethical discourse? Recall how a telos is determined according to Aristotle. It is our desires based on our character qualities, namely dispositions, that determine the end where "dispositions are the formed states of character in virtue of which we are well or ill-disposed in respect of the emotions" (NE II.v.2). In other words, telos is determined by desires that arise due to our character qualities, which are well or ill-disposed with respect to emotions. There are three kinds of desires according to Aristotle: epithimia, bodily desires such as hunger; thimia, passionate desires such as anger; and boulesis, i.e., wish. To wish is only possible for human beings, says 
Aristotle, for it involves thought about future. But we should rather claim that a wish involves understanding and deliberation about future, accompanied by a higher-order emotion, namely, love. If we try to consider any desire that is aroused by love, it is always an aspiration aiming at some future state. The proper motivation behind our wish is our love for what we imagine to be the case in future as the most beautiful. Even our love for another human being depends on our wish to live close to them. Love in this sense is not, as it is usually misunderstood, a desire to possess another being. That is the structure of basic bodily desires, such as hunger. Against this, love always aims at a future state of well-being. In this sense, Diotima's view as explained by Socrates in Plato's Symposium is right: love is the motivation behind our wish to produce beauty, either spiritual or bodily, and due to our love of life we wish to be immortal in this way.

I have claimed that Gönül, i.e., the faculty of love, is the faculty of understanding and deliberation based on teleological reasoning and results with an evaluative judgment accompanied with a wish, the desire that is associated with love. Aristotle also agrees that wish is distinctively a human desire. But his explanation for this is different. Since Aristotle believes that mind is the distinctive capacity of humans and wish involves thought, he concludes that animals cannot have wishes. From our perspective, it is true that wish is a distinctively human phenomenon but for different reasons. Wish involves understanding and deliberation with respect to teleological reasoning, a process that is guided by love, and this evaluative discourse, which we call ethical discourse, is lacking in animals. For the faculty of Gönül to function properly, of course, the faculty of mind should also be at work to some extent. We should not only understand and deliberate about the future state which we wish to achieve through love, but we should also know the external circumstances. As I stressed before, Gönül is a higher capacity that presupposes the faculty of mind.

I also claimed that Gönül is the faculty that distinguishes humans from animals. This just means that the ability to engage in ethical discourse is what distinguishes humans from animals. But animals also have the capacity of mind. Since animals (or at least some animals) have intelligence, they can follow mechanical reasoning; they can know what will follow from what. What they do lack, however, is teleological reasoning; they do not determine a telos for themselves, and do not consciously aim at their unconscious telos of survival and reproduction. In other words, animals can know the material world, but cannot understand and deliberate about their own world. Their telos is embodied in their lives; it is instinctual. Humans can go beyond their natural telos of survival and reproduction through love. Humans are telos-creating animals, telos is not given to humans. Ethical discourse would be pointless otherwise; for ethical discourse consists of determining a telos through understanding and deliberation.

I have claimed that animals lack the capacity of Gönül and that in the narrow sense Gönül is the capacity of love and in the broader sense it is the capacity of emotions. It might not sound awkward to claim that animals do not feel love; for their attachment to another being is always on the basis of unconscious benefit. But if we take Gönül in the broad sense, does this mean that animals also lack 
all kinds of emotions? That would be an outrageous claim, given the way we use the notion of emotion in common language. Now, we shall need to make a distinction between two kinds of feelings: passions and emotions. Passions I would call those feelings that arise in animals including humans, due to mechanical reasons. Emotions I would call those feelings that arise only in humans in connection with understanding and deliberation due to teleological reasons. In other words, emotions are higher-order feelings than passions.

Gönül allows us humans to engage in ethical discourse. Ethical discourse aims at the determination of an ethical judgement accompanied by a wish, which requires teleological reasoning based on understanding and deliberation through emotions. In this sense, not all of our desires are a result of ethical discourse. We have first-order desires shared with animals, which Aristotle calls epithimia and thimia, and which we called bodily desires and passionate desires. First-order desires, namely, bodily and passionate desires, arise due to mechanical reasons. But humans are able to prevent the immediate action based on these desires, for they can form a second-order desire, namely, a wish, which is based on teleological reasons. Wish is the name of the desire that requires emotions rather than passions, and emotions, as I claimed, are higher-order feelings without which there would not be understanding and deliberation. In this sense, the outlined perspective helps also to avoid the Humean question concerning how reason is capable of combatting passion. For it is not reason but wish, which is also a form of desire, that prevents another lower-order desire to be followed. This does not mean that first-order desires will always be suppressed by a second-order desire called wish. If our wish is weak, that is to say, if we do not love wholeheartedly what we wish, and if we have not educated our first-order desires, then first-order desires can go wild and win over. This is the situation of akrasia, namely, incontinence.

I have so far addressed the problem of telos as if it could only be determined by love. I would like to make a qualification now. It seems that all other kinds of emotions can also determine a telos, which might not be good at all. We might have bad wishes. But this is exactly what might go wrong in ethical discourse when our character is corrupt. Since this means that we are ill-disposed in respect of emotions, our telos, as well as our wishes, may turn out to be bad. Hence, not all of our second-order desires are worth following either. In Aristotelian terms, a good wish consists of the kind of wish that a "sevgidolu" person would wish for, where "sevgidolu" in Turkish is the name of a virtue which literally means "full of love."

At this point, we need to rebut a possible objection. It is firmly believed that intelligence is universal among humans, and emotions vary from person to person. How is it then possible to establish ethics based on emotions without falling onto relativism? I have always found the belief in the universality of intelligence problematic, for a mere observation among people we know falsifies this; some are more intelligent than us, some others are less. It is true that mind as a capacity is universal, but so is Gönül. If it is true that the way Gönül operates varies from person to person, so do the workings of the mind vary. In other words, I argue that mind and Gönül are universal capacities common to all healthy human beings, but the way in which they are actualized depends on various parameters. What these 
parameters are, is outside our concern here. All I want to say, which Aristotle also knew, is that understanding the truth concerning ethical issues requires a certain kind of character, which means to be well-disposed with respect to emotions. But this is an epistemological requirement. Even if there were no such characters on earth, ethical truths for this reason would not be null. The same is true for scientific truths; they also require a certain frame of mind to be known. This is also an epistemological, not an ontological, requirement. In short, relativism about the way in which mind and Gönül function from person to person do not lead to relativism about ethical and scientific truths.

To conclude: the introduction of the concept of Gönül in order to develop a thesis in philosophical anthropology, supported by etymological connections among certain concepts in Turkish, allows us to understand the relevance of love in particular, and emotions in general, in ethical discourse. Nonetheless, more work needs to be done to give a more comprehensive view in philosophical anthropology, something which I shall leave for future studies.

\section{Bibliography}

Aristotle, The Art of Rhetoric, transl. J.H. Freese, Cambridge 2006.

Aristotle, The Nicomachean Ethics, transl. H. Racham, Cambridge 1934.

Korkut Raptis B., "Gönlünce Yaşamak: Güzel Bir Yaşamın İki Koşulu," Felsefelogos 53 (2014), pp. 137-157.

Korkut Raptis B., The Narrative Nature of Ethical Discourse (Ph.D. Dissertation in Philosophy), University of Notre Dame, IN, USA 2011.

Scheler M., The Human Place in the Cosmos, transl. M.S. Frings, Evanston 2009. 